\title{
COMPARING CERTIFICATION AND SELF-REGULATION
}

\author{
Jan Mysliveček
}

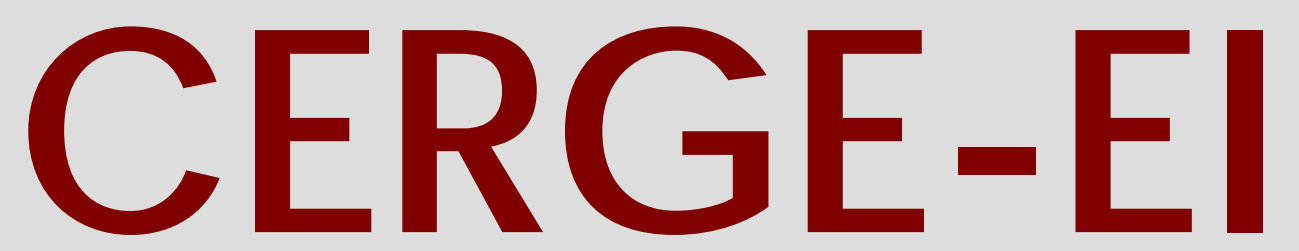

Charles University Centerfor Economic Research and Graduate Education Academy of Sciences of the Czech Republic Ec onomic s Institute 


\title{
Working Paper Series 361 (ISSN 1211-3298)
}

\section{Comparing Certification and Self-regulation}

\author{
Jan Mysliveček
}

CERGE-EI

Prague, September 2008 
ISBN 978-80-7343-161-7 (Univerzita Karlova. Centrum pro ekonomický výzkum a doktorské studium)

ISBN 978-80-7344-150-0 (Národohospodářský ústav AV ČR, v.v.i.) 


\title{
Comparing Certification and Self-regulation Jan Mysliveček 用
}

CERGE-EI $\dagger$

\begin{abstract}
:
I compare certification and self-regulation, two widely used quality assurance mechanisms in markets where consumers do not observe the quality of goods. Certification is a mechanism in which an external firm offers a certificate to producers who undergo a testing procedure, issues the certificate if they meet the certifier's standards and collects the certification fee. Self-regulation is a mechanism in which a club of firms in the industry adhere (or not) to a self-imposed code of conduct and benefit from the club's reputation. I show that if the testing technology is perfect and costless, the choice of standards and fees by the certifying organization $(\mathrm{CO})$ is welfare inferior, while the self-regulatory organization (SRO) chooses a welfare optimal fee, and I identify conditions under which the SRO also chooses optimal standards. If the testing technology is costly and imperfect, this result is not necessarily valid and depends on the difference between the costs of the testing technology available to the CO and SRO.
\end{abstract}

\begin{abstract}
Abstrakt:
Tento článek porovnává certifikaci a sebe-regulaci, dvě běžně využívané metody zaručení kvality na trzích, kde spotřebitelé nejsou schopni rozpoznat kvalitu výrobku. Certifikace je prováděna externí firmou za poplatek. Ti výrobci, kteří úspěšně projdou testem, obdrží certifikát. Druhá metoda je sebe-regulace, kdy se firmy sdružené do sebe-regulující organizace, kontrolují navzájem a společně si stanovují požadované standardy. Členové sdružení pak využívají reputaci celého sdružení. Získané výsledky ukazují, že pokud je testovací technologie bezchybná a bezplatná, standardy a poplatky zvolené zisk maximalizující certifikační autoritou nejsou optimální, zatímco sebe-regulující organizace volí optimální poplatek a v některých situacích i optimální standard. Pokud je testovací technologie nákladná nebo není perfektní, tento výsledek není nutně platný a závisí na rozdílů nákladů mezi certifikační a sebe-regulační autoritou.
\end{abstract}

Keywords: Quality assurance, asymmetry of information, certification, self-regulation JEL Classification: D02, D45, D71, D72, D82, L14, L15, L21, L38, L43, L51

* This research was partly conducted during my visit at the University of Californa, San Diego, thanks to support by the Fulbright Commission. This research was also supported by grant No. $7743 / 2007$ from the Grant Agency of Charles University. I would like to thank Junghun Cho, Libor Dušek, Randall Filer, Eva Hromadková, Katarína Kálovcová, Peter Katuščák, and Avner Shaked for their comments and to Andreas Ortmann for his patient supervision and support. All errors are mine.

$\dagger$ CERGE-EI is a joint workplace of the Center for Economic Research and Graduate Education, Charles University, and the Economics Institute of Academy of Sciences of the Czech Republic.

Address: CERGE-EI, PO Box 882, Politických vězňů 7, 11121 Prague, Czech Republic. E-mail: jan.myslivecek@cerge-ei.cz. 


\section{Introduction}

I study markets in which producers have a choice ve the quality they produce, but this quality is unobservable for consumers. This asymmetry of information often leads to an adverse market outcome such as only low-quality products being traded even if high quality is valued by the consumers (Akerlof (1970), Leland (1979)). There are several mechanisms to prevent such adverse outcomes. These mechanism are, among others, producer's reputation (via repeated interaction), advertising, warranties, certification, and self-regulation.

When the information asymmetries are particularly severe 11 certification and self-regulation often seem to work better than other mechanisms, at least theoretically. This is so because both of these mechanisms are based on the third party - an organization whose reputation replaces the need for individual reputation building by each producer, which simplifies learning for consumers. This organization must be able to observe the (signal of) quality itself. In the case of certification, such an organization is an external, possibly but not necessarily profit-maximizing, firm. In the case of self-regulation, the organization is formed by a group of producers in the industry. Typically, such an organization sets some quality standard $q_{S}$ and fee for testing a producer. When a producer applies for a certificate/membership, he pays the fee, the quality of its products is inspected and if it meets the quality standards, he is allowed to use the certificate or the membership. The mechanisms with which a single organization's reputation may replace individual reputations is describe in papers by Biglaiser and Friedman (1994) and Biglaiser (1993). Even though the honesty of this organization cannot be taken for granted (see Strausz (2005) for certification and Nunez (2001) for selfregulation), both mechanisms are widely used as a means of quality assurance for many professions like doctors, lawyers and accountants (Kleiner 2006), environmental aspects of many industries (Podhorsky 2006) and charities (Ortmann, Svitkova, and Krnacova 2005).

Even though the honesty of a single organization, such as a certifier or a self-regulating organization, is easier to sustain, this organization may use its monopoly position to ex-

\footnotetext{
${ }^{1}$ Examples include situations where there are many producers and consumers who shop infrequently so that they cannot establish individual reputations; when warranties do not work due to the moral hazard, etc. One can think of charities (a large number of various charities with quality unobservable before or after the donation), organic farmers, and also lawyers, dentists and other doctors; see Ortmann, Svitkova, and Krnacova (2005), Kleiner (2006), Shaked and Sutton (1981).
} 
tract rents (see Shaked and Sutton (1981) and Lizzeri (1999) for theoretical arguments). Presumably, the rent-extraction motive might be stronger in the case of a self-regulatory organization (SRO), because such organization sets standards to benefit its members. Yet, I show that such intuition may be sometimes wrong. The profit maximizing $\mathrm{CO}$ aims to extract rents from producers who in turn try to extract rents from consumers. These distortions may be larger than those caused by self-regulation.

There is empirical evidence that when the regulation of an industry is changed from certification to self-regulation, the average quality of goods may increase only slightly, if at all (Kleiner 2006). This evidence is sometimes used to argue that self-regulation is not a better form of regulation than certification (ibid.). I show formally that such reasoning is misleading, because enforcing high quality may be inefficient when consumers' valuation of a marginal increase in quality is smaller than the marginal costs required to produce it. Thus, higher standards do not necessarily translate into higher welfare. Comparison of certification and self-regulation thus must be based on welfare, which depends on both prices and quality standards, not just the latter.

I argue that although certification and self-regulation are very similar ${ }^{2}$ the main difference comes from different objectives of the $\mathrm{CO}$ and SRO. While certifying organizations are firms not directly linked with the producers, the self-regulatory organizations are formed by groups of producers and the SROs themselves do not generate any profit but they are motivated by profits of its members. I focus on how this difference in the objectives impacts the choice of standards and the fees. I show that because the SRO itself does not aim at extracting rent from the producers, it chooses a lower fee than a profit-maximizing CO.

Since certifiers are often not-for-profit organizations, I extend our model to analyze other objective functions. In particular, I study the cases when certifiers maximize revenue of producers, number of certified producers or standards. I also analyze the behavior of the $\mathrm{SRO}$ in the case when it can directly limit the number of members.$^{3}$

\footnotetext{
${ }^{2}$ In both cases, the consumers observe a single message (label of membership or certificate) and face in principle the same information asymmetry; producers can choose their quality and whether they will apply for a certificate or membership. The producers also have the same incentives to "cheat"- obtain a certificate of quality they do not produce.

${ }^{3}$ In many countries, anti-trust regulations allow quality standards (e.g., difficulty of tests, length of supervised practice), but often do not allow direct regulation of the number of members in the organization.
} 
These results are based on two related key assumptions. First, I assume that the testing technology is perfect. This assumption greatly simplifies the analysis but may introduce a bias in favor of one of the institutions. If the internal incentive structure in the presence of imperfect testing technology makes is more difficult for the SRO to enforce high quality standards (see Nunez, 2001 and 2007) in contrast to certification (De and Nabar 1991), then the benefits of self-regulation may completely disappear. One thus may expect selfregulation to work better and to be more prevalent in industries where quality is easier for experts to observe, while one may expect certification in industries where the quality evaluation is more difficult. In the concluding section, I also discuss the possibility to model the differences in standards enforcement as differences in costs.

This analysis applies to a variety of professions and industries. In many countries, lawyers, doctors, dentists, accountants and architects are self-regulated (Kleiner 2006). Certification is widely used in non-profit sectors, such as charities (Ortmann, Svitkova, and Krnacova 2005) and hospitals (by American Hospitals Associations). It is also used by for-profit firms to document environmental aspect of production (Podhorsky 2006) and by professionals to prove expertise in the industry (Financial Risk Manager (FRM), Microsoft Certified Professional and many others). While it seems that if one industry or profession is self-regulated in one country, it will be self-regulated in other countries (typically true for lawyers, doctors and accountants), there certainly are exceptions. For example, charities are mostly certified throughout Western Europe and the USA, yet there exists a self-regulatory organization of charities in the Czech Republic. Also, as Kleiner (2006) documents, it is not unusual to find a change in the form of regulation from certification to self-regulation. This paper is a first step towards understanding these differences and explaining why certain industries are persistently self-regulated or certified.

The next section shortly reviews the literature and basic assumptions of the model. The third section provides the model and its analysis. Next, I discuss the impact of my assumptions on the result and possible extensions and suggestions for future research. The final section concludes. Most proofs are provided in the Appendix.

As there are exceptions to this rule (e.g., notaries in some countries), I analyze the impact of such regulations. 


\section{Certification and Self-Regulation}

I generalize the model of self-regulation by Shaked and Sutton (1981). They construct a model of self-regulation in which the quality produced by each potential producer and the distribution of producers is fixed. This allows them to focus on the incentives of the SRO to choose minimal standards without imposing a specific objective function of the selfregulatory organization (SRO). However, the fixed distribution of potential producers implies that the SRO may improve its standards only by restricting its size. Instead, I analyze a model in which quality produced and standards are a choice variable.

Such simplifying assumption allows me to focus on the incentives of the SRO/CO to set standards without a direct link between quality and number of producers. This generalization has its cost: I need to assume an objective function. Since the SRO is formed and managed as a non-profit organization by its for-profit members, I assume that the SRO maximizes total profit of its members..$^{4}$

This approach differs from other papers on self-regulation. Nunez (2001) and Nunez (2007) assume that the SRO cares about its own reputation and possible bribes. It is assumed that the SRO has a fixed size and pre-determined standards. Its members decide on the individual extent of cheating and the regulatory organization decides on the level of enforcement and whether to inform consumers if it finds cheating. The analysis thus focuses on the enforcement of the standards and not on how they are established. If revealed cheating reduces the reputation of the SRO enough, then the SRO does not have sufficient incentives to monitor its members and they are cheating in equilibrium. If a revelation of cheating increases the value of the SRO's reputation, then there exists an equilibrium with a positive level of enforcement and revelation. In addition, if a member may bribe the SRO not to reveal cheating, there exists an additional, welfare suboptimal equilibrium in which the SRO enforce the standards but does not reveal the cheating and collects bribes.5

This analysis suggests that the SRO is likely to suffer from internal incentive problems that prevents it from fully enforcing the standards. However, this result is based on the

\footnotetext{
${ }^{4}$ This is not the only option but seems the most natural one. Other options are discussed in the section below.

${ }^{5}$ The outcome depends on the parametrization. For a summary of the results, see p. 225 of Nunez (2007).
} 
assumption that the SRO is motivated by the value of its reputation. If the SRO is motivated by the profits of its members, it has stronger incentives to enforces the standards, when profits of its members depend on it. I focus on the case when the SRO (and also CO) has access to perfect testing technology. ${ }^{6}$ Such assumption greatly simplifies the analysis but also reduces the impact of the internal structure on quality standards. The results thus obtained may be sensitive to this assumption and in the concluding section, I discuss how the results would change if this assumption would be relaxed.

The idea of comparing certification and self-regulation is new in the literature. There is one notable exception: Shapiro (1986). He focuses on input regulation when higher initial investment makes production of high quality cheaper. He compares licensing (similar to self-regulation in our terminology), a requirement to make a minimal investment with certification, an informational device that reveals investment to the consumers but does not regulate it. Shapiro shows that licensing and certification benefit high valuation consumers at the expense of low valuation consumers. Shapiro assumes that the consumers are eventually able to learn the true quality of the products, so even laissez-faire allows some high quality production, and certification may be welfare worsening because it leads to excessive investment (which is used as a signaling device). In Shapiro's model, there are only two levels of quality, high and low, and these levels are exogenously given. My model is more general: there will still be only two levels of quality traded on the market, but those levels will be endogenously determined. The model also differs in the assumption about the ability of consumers to learn the true quality. I assume that an individual producer's quality is completely unobservable.

I analyze the case where there exists only one signal of quality to the consumersmembership in a SRO or a certificate from a CO. This structure is very common (Kleiner (2006), Lizzeri (1999), Svitkova and Ortmann (2006)) but theoretically puzzling because the certifier (or the SRO) learns more than only whether the producer meets the standard. Lizzeri (1999) shows that it is optimal for a profit-maximizing certifier to reveal only a

\footnotetext{
${ }^{6}$ This assumption requires that the $\mathrm{CO}$ or the SRO is able to tell whether a product meets requires standards. This is somewhat weaker than the assumptions of other authors (such as Lizzeri, 1999) that require that the $\mathrm{CO}$ is able to tell what is the level of quality exactly.
} 
"pass/fail" signal. In his model, the quality of a product is exogenously given in each period and a certifier learns the quality perfectly. Among all possible disclosure rules, the "pass/fail" rule is the most profitable one if the quality may have negative value to consumers. If even the expected value of quality is negative for the consumer, "pass/fail" is the only optimal rule.

The model by Biglaiser and Friedman (1994) shows that the informational advantage of a certifier (middleman in their terminology) does not need to come from perfect testing technology, but from his ability to aggregate information from consumers and using this information to "drop" (remove the certificate) from producers who attempt to cheat in quality.

\section{$3 \quad$ Model}

I model certification and self-regulation as a game with three groups of heterogeneous players: consumers, producers and a certifying or self-regulatory organization $(\mathrm{CO} / \mathrm{SRO})$. I generalize previous models of certification by assuming that the quality of production can be of any value from zero to infinity. I study the case in which consumers cannot observe any information about a producer's quality (no individual reputation), but they know the average quality of certified products.

I assume that the certifying and/or self-regulatory organization has access to costless perfect testing technology $]^{7}$ and sets standards to $q_{S} \geq 0$. Observing this standard, producers face a choice between producing zero quality (without a certificate) and quality $q_{S}$ and applying for a certificate. Thus, similarly to previous research, producers face a binary choice between high $\left(q_{s}\right)$ and low (0) quality. $]^{8}$ but, in contrast to the previous literature,

\footnotetext{
${ }^{7}$ I analyze the case of costly, but still perfect, testing technology in one of the extensions.

${ }^{8}$ These two assumptions imply that a producer will not produce any other quality than 0 or $q_{S}$ in equilibrium. First, perfect detection technology means that the certifier does not make mistakes when it evaluates whether a product is of at least standardized quality. Second, there are no individual reputations of producers.

Relaxing each of these assumptions is likely to lead to a dispersion of quality. For example, in the case of imperfect testing technology, low-cost firms might produce quality higher than required because it increases the probability of passing noisy tests. High-cost firms might under-invest into quality hoping that they will pass nonetheless. It is not clear what will be the overall impact on the average quality.
} 
the levels of quality are endogenously determined. This allows us to compare not only fees the $\mathrm{CO} / \mathrm{SRO}$ will charge, but also quality standards they will select and enforce. Note that there will be only two qualities traded on the market $\left(q_{S}\right.$ for certified products and 0 for not certified). Moreover, I analyze equilibria in which consumers' expectations about $q_{S}$ are fulfilled (rational expectations equilibria).

Apart from the endogenous quality and perfect testing technology, I make the following assumptions. There is a large number of heterogeneous firms,$^{9}$ each characterized by cost parameter $\alpha_{i} \in[0, \infty]$; their density is described by a continuous function $f(\alpha)$ and their distribution by $F(\alpha)$. Each firm has an opportunity to produce one unit of output at quality $q$ and at $\operatorname{costs} g(q, \alpha)$. The cost function $g(q, a)$ is assumed to satisfy

$$
\begin{gathered}
g(0,0)=g_{q}(0,0)=g_{\alpha}(0,0)=0, g(q, \alpha)>0 \\
g_{q}(q, \alpha)>0, g_{\alpha}(q, \alpha)>0, g_{q \alpha}(q, a)>0, g_{q q}>0 \text { for } q>0, \alpha>.0
\end{gathered}
$$

These assumptions mean that it is costless to produce zero quality and that the costs are increasing in quality $q$ and cost type $\alpha$. Moreover, the costs are assumed to be convex in the quality and an increase in the standard increases the costs of high- $\alpha$ (ie., high-cost) producers more than it does for low- $\alpha$ producers.

Due to the perfect testing technology, only firms that produce standards $q_{S}$ can successfully pass the test and thus only they can sell their product with the "label" of the CO/SRO. Products without a "label" are (perceived by consumers as being) of zero quality ${ }^{10}$ and are sold on a separate market.

Formally, the game has two stages.

1. In the first stage, a $\mathrm{CO}$ or SRO publicly announces standards $q_{S}$ and fee $C$ to maximize its profit $(\mathrm{CO})$ or total profit of its members (SRO).

\footnotetext{
${ }^{9}$ Each firm thus has insignificant impact on the market and therefore can take market price, quality and other characteristics as not depending on its own decisions. This also justifies the assumption that producers do not have individual reputations.

${ }^{10}$ The zero-quality segment of the market can be interpreted in two ways. First, the certification/selfregulation can be interpreted as voluntary, and zero-quality segment is a competitive, unregulated market where producers do not invest into quality. The competitive nature of the market prevents them from making any profit. Second, certification/self-regulation may be obligatory and producers who do not apply for a certificate/membership are prevented from operating on the market and thus make zero profit.
} 
2. In the second stage, consumers decide whether to purchase from a certified producer, taking price $p$ and expected quality $q$ as given. Simultaneously, firms choose how much to invest into quality, taking price $p$, fee $C$ and standards $q_{S}$ as given and whether to apply for a certificate. Price $p$ is set competitively.

\subsection{Second stage}

Since every producer (with cost parameter $\alpha$ ) has a zero outside option, he will invest into quality and certification if and only if

$$
p-C-g(q, \alpha) \geq 0
$$

which implies, due to our assumptions on $g$, existence of a unique value of parameter $\tilde{\alpha}\left(C, q_{S}, p\right)$ such that only producers with $\alpha \leq \tilde{\alpha}\left(C, q_{S}, p\right)$ will apply for a certificate, each investing $g\left(q_{S}, \alpha\right)$.

There is a large number of consumers, each willing to buy up to one unit of good. Their utility depends on the expected ${ }^{11}$ quality $q$, price $p$, their budget $M$ and individual preference for quality $\beta$, which is distributed according to the continuous density $w(\beta)$ and distribution functions $W(\beta)$. A consumer will prefer a certified product of expected quality $q$ and of price $p$ if

$$
U(\beta, M-p, q) \geq U(\beta, M, 0), \beta \in[0,1]
$$

Consumers prefer to have more money rather than less money $\left(U_{M} \geq 0\right)$, they value quality $\left(U_{q} \geq 0\right)$ and consumers with higher $\beta$ value quality less than those with lower $\beta$ (ie., $\left.U_{\beta} \leq 0\right){ }^{12}$ Thus, there exists a single consumer who is indifferent between buying at price $p$ and expected quality $q$, whom we will denote $\tilde{\beta}\left(p, q_{S}\right)$. Consumers with $\beta \leq \tilde{\beta}\left(p, q_{S}\right)$ demand one unit of good of quality $q>0$, while others do not buy anything.

Since firms with $\alpha \leq \tilde{\alpha}\left(C, q_{S}, p\right)$ apply for certification, the supply is $F\left(\tilde{\alpha}\left(C, q_{S}, p\right)\right)$. Simi-

\footnotetext{
${ }^{11}$ Formally, I analyze a rational expectations equilibrium in which quality expectations are fulfilled.

${ }^{12} \mathrm{I}$ will assume that the inequalities are strict for $q>0$. Moreover, I will assume that $U_{\beta}(\beta, M, 0)=$ 0 because it simplifies the results without any significant loss of generality. Note that the more usual assumption $U_{\beta q}<0$ for $q>0$ implies that $U_{\beta}<0$, and thus would be also sufficient for our results.
} 
larly, consumers with $\beta \leq \tilde{\beta}\left(p, q_{S}\right)$ will be demanding these goods and there is $W\left(\tilde{\beta}\left(p, q_{S}\right)\right)$ of them. I will assume that there exists a market equilibrium in which supply is equal to the demand, at least for some range of quality standards $q_{S} \in\left[0, \bar{q}_{S}\right]$

$$
\int_{0}^{\tilde{\beta}\left(p, q_{S}\right)} w(\beta) d \beta=\int_{0}^{\tilde{\alpha}\left(C, q_{S}, p\right)} f(\alpha) d \alpha \Longrightarrow p^{*}\left(C, q_{S}\right) .
$$

This equilibrium condition determines price $p^{*}\left(C, q_{S}\right)$. For further analysis, I will use the "reduced-forms" of functions $\tilde{\alpha}, \tilde{\beta}$, which are denoted by $\alpha^{*}, \beta^{*}$ and defined as

$$
\alpha^{*}\left(C, q_{S}\right)=\tilde{\alpha}\left(C, q_{S}, p^{*}\left(C, q_{S}\right)\right), \beta^{*}\left(C, q_{S}\right)=\tilde{\beta}\left(p^{*}\left(C, q_{S}\right), q_{S}\right) .
$$

The second stage of the game thus determines price $p^{*}\left(C, q_{S}\right)$ and quantity $F\left(\alpha^{*}\left(C, q_{S}\right)\right)=$ $W\left(\beta^{*}\left(C, q_{S}\right)\right)$, as a function of the standards $q_{S}$ and fee $C$ set in the first stage. Analysis of the impact of the first stage on the equilibrium levels of prices, supply and demand is summarized in the following lemma.

Lemma 1. An increase in fee $C$ increases equilibrium prices but reduces supply and demand.

$$
1>\frac{\partial p^{*}\left(C, q_{S}\right)}{\partial C}>0, \frac{\partial \alpha^{*}\left(C, q_{S}\right)}{\partial C}<0, \frac{\partial \beta^{*}\left(C, q_{S}\right)}{\partial C}<0
$$

An increase in standards $q_{S}$ always increases equilibrium price $\frac{\partial p^{*}\left(C, q_{S}\right)}{\partial q_{S}}>0$, but leads to a decrease in demand and supply if and only if

$$
g_{q_{S}}\left(q_{S}, \alpha^{*}\left(C, q_{S}\right)\right)>\frac{U_{q_{S}}\left(\beta, M-p^{*}\left(C, q_{S}\right), q_{S}\right)}{U_{M}\left(\beta, M-p^{*}\left(C, q_{S}\right), q_{S}\right)} .
$$

Proof of this lemma is provided in the Appendix and uses comparative statics with respect to $q_{S}$ and $p_{S}$. The result is intuitive: an increase in the cost of certification $C$ translates into an increase in the price of products $p^{*}$, but fewer products are traded because the higher price reduces demand for certified products. The overall impact on the supply

\footnotetext{
${ }^{13}$ Further assumptions about $g$ are necessary to show that there exists the highest possible quality traded $\bar{q}_{s}$. These conditions are derived in section 3.5.1, where the behavior of the standard maximizing non-profit certifier is analyzed.
} 
is negative because the price increases less than fee $C$ does and thus overall revenue for the firm $p-C$ decreases, which also decreases the supply. Further, an increase in the standards increases the value of the product for the consumer and costs to the firms and leads to an increase in price $p$. The impact of an increase in standards on supply and demand can be intuitively seen when the condition is rewritten as ${ }^{14}$

$$
g_{q_{S}}\left(q_{S}, \alpha^{*}\left(C, q_{S}\right)\right) U_{M}>U_{q_{S}}
$$

In this form, the left-hand side describes the marginal costs (in utility terms) of an increase in standards while the right-hand side describes the benefit it has for the consumers. If the marginal consumers' benefit is higher than the marginal cost, an increase in standards generates positive surplus, which allows further trade and increases equilibrium demand and supply.

\subsection{Behavior of the certifier}

In the first stage of the game, the organization chooses the standard $q_{S}$ and fee $C$. I first focus on the behavior of a profit-maximizing certifier. In Section 3.5, I extend our analysis by analyzing alternative objective functions.

\subsubsection{Profit-maximizing certifier}

When the testing technology is costless, the objective function of the profit-maximizing certifier is

$$
\max _{C, q_{S}} C \int_{0}^{\alpha^{*}\left(q_{s}, C\right)} f(\alpha) d \alpha=\max _{C, q_{S}} C F\left(\alpha^{*}\left(q_{S}, C\right)\right) .
$$

The optimal interior choice of standard $q_{S}$ and certification fee $C$ is thus described by the first order conditions

$$
\begin{aligned}
& {[C]: F\left(\alpha^{*}\left(C, q_{S}\right)\right)+C f\left(\alpha^{*}\left(C, q_{S}\right)\right) \frac{\partial \alpha^{*}\left(C, q_{S}\right)}{\partial C}=0} \\
& {\left[q_{S}\right]: C f\left(\alpha^{*}\left(C, q_{S}\right)\right) \frac{\partial \alpha^{*}\left(C, q_{S}\right)}{\partial q_{S}}=0 .}
\end{aligned}
$$

\footnotetext{
${ }^{14}$ For simplicity, I often write $U$ instead of $U\left(\beta, M-p^{*}\left(C, q_{S}\right), q_{S}\right)$, where the arguments are obvious.
} 
I assume that there exists an interior solution.

Lemma 2. In equilibrium, I have

$$
g_{q_{S}}\left(q_{S}, \alpha^{*}\left(C, q_{S}\right)\right)=\frac{U_{q_{S}}}{U_{M}}
$$

and

$$
\frac{\partial p^{*}\left(C, q_{S}\right)}{\partial q_{S}}=\frac{U_{q_{S}}}{U_{M}}, \frac{\partial \alpha^{*}\left(C, q_{S}\right)}{\partial q_{S}}=\frac{\partial \beta^{*}\left(C, q_{S}\right)}{\partial q_{S}}=0 .
$$

These conditions are intuitive - the CO chooses standards so that the increase in costs for a marginal producer equals the increase in price. Other certified producers are not relevant for the decision made by certifiers because they make positive profits. Also, standards are chosen so that the maximal number of producers applies for certification, given the fee $C$.

Overall, the certifier's choice of certification fee and standards can be separated into two hypothetical parts. First, for any given certification fee $C$, the certifier chooses standards so that the maximal number of producers applies:

$$
\frac{\partial \alpha^{*}\left(C, q_{S}\right)}{\partial q_{S}}=0
$$

Given the relationship between the certification fee and the number of producers applying for certification, it then chooses the optimal fee $C$. This result will be useful later because it describes the optimal standards even for exogenously given fees $C$.

\subsection{Behavior of the self-regulatory organization}

I analyze the behavior of a self-regulatory organization (SRO) formed by firms in the industry that sets standards to maximize total profit of its members. 15 The SRO can reject or accept

\footnotetext{
${ }^{15}$ In general, these organizations set the quality standards based on the preferences of their members. This leads to some ambiguity in their objective function, since the SROs themselves have not-for-profit status. Thus, the question is whether the SRO maximizes the profits of their highest/lowest quality members, the average profit, or the total profit. I start with probably the most realistic and simplest approach of total profit maximization. Other approaches often lead to corner solutions. For example, maximizing average profit immediately leads to zero-size SRO with only the highest quality (lowest costs of quality) firms, unless there are economically significant fixed costs.
} 
its members depending only on their quality of production ${ }^{16}$ This allows the SRO to choose its size by choosing the standards, but not directly. If the SRO maximizes total profit of its members, it does not need to charge any fee $C$, but sets only some standards $q_{S}$ in order to maximize its profit. Charging positive fees that are then returned to the members of the organization would not change their behavior and would not affect the results.

\subsubsection{Quality restrictions only}

Without adding any technical complications, I can analyze a more general problem when the SRO charges positive fee $C$, but the money thus collected belongs to the government. The problem for the SRO that charges exogenously given fee $C$ and tries to choose standards so that it maximizes the profit of its members is

$$
\max _{q_{S}} \int_{0}^{\alpha^{*}\left(C, q_{S}\right)}\left(p\left(C, q_{S}\right)-g\left(q_{S}, \alpha\right)-C\right) f(\alpha) d \alpha .
$$

The first order condition i: 17

$$
\int_{0}^{\alpha^{*}\left(C, q_{S}\right)}\left(\frac{\partial p\left(C, q_{S}\right)}{\partial q_{S}}-\frac{\partial g\left(q_{S}, \alpha\right)}{\partial q_{S}}\right) f(\alpha) d \alpha=0 .
$$

Since the term $\frac{\partial p\left(C, q_{S}\right)}{\partial q_{S}}$ does not depend on $\alpha$, the equilibrium conditions can be written as

$$
F\left(\alpha^{*}\left(C, q_{S}\right)\right) \frac{\partial p\left(C, q_{S}\right)}{\partial q_{S}}=\int_{0}^{\alpha^{*}\left(C, q_{S}\right)} \frac{\partial g\left(q_{S}, \alpha\right)}{\partial q_{S}} f(\alpha) d \alpha
$$

Lemma 3. If $\frac{\partial^{2} g\left(q_{S}, \alpha\right)}{\partial \alpha \partial q_{S}}>0$, then in the interior solution the SRO chooses standards such that the marginal costs for a marginal firm $\left(\alpha^{*}\right)$ of its members exceed the relative valuation of the marginal consumer

$$
g_{q_{S}}\left(q_{S}, \alpha^{*}\left(C, q_{S}\right)\right)>\frac{U_{q_{S}}}{U_{M}}
$$

The intuition is that producers with $\alpha<\alpha^{*}$ face lower increases in the costs of pro-

\footnotetext{
${ }^{16}$ This means that the SRO has to accept an application from any firm that meets the required standard. It also implies that the (only) punishment for not meeting required standards is exclusion from the organization.

${ }^{17}$ It is easy to see that there is an interior solution. Clearly, zero standard implies zero total profit. Also, a very large standard implies costs larger than the price if the consumers' valuation of quality is bounded from above.
} 
duction but the same increase in price. Therefore, the SRO chooses standards higher than those that would equalize the marginal cost and revenue for marginal producer $\alpha^{*}$ because such standards would leave "money on the table" - an increase in standards would increase revenues more than the costs for all producers. Note that this result holds for any $C$.

\subsubsection{Quality and quantity restrictions}

I extend the previous analysis by considering an alternative form of regulation, under which the SRO is able to restrict the number of its members. This contrasts two possible forms of regulation of the SRO. In the previous case, the SRO was free to choose standards $q_{S}$, but it had to admit every producer who was able to meet this standard. Alternatively, the SRO might be given the right to select the number of members. In the first case, the marginal producer will have zero profit. In the second case, even the highest cost member may be making positive profit.

Since

$$
\frac{\partial \alpha^{*}\left(C, q_{S}\right)}{\partial C}<0
$$

the function $n=\alpha\left(C, q_{S}\right)$ is invertible in $C$. Thus by controlling the minimum profit its members must make, the SRO is able to control the number of members. In such a situation, the total profit-maximizing organization will have the following objective function

$$
\max _{q_{S}, C} \int_{0}^{\alpha^{*}\left(C, q_{S}\right)}\left(p\left(C, q_{S}\right)-g\left(q_{S}, \alpha\right)\right) f(\alpha) d \alpha
$$

Lemma 4. The SRO that can restrict the number of its members directly will still choose $C, q_{S}$ such that

$$
g_{q_{S}}\left(q_{S}, \alpha^{*}\left(C, q_{S}\right)\right)>\frac{U_{q_{S}}}{U_{M}}
$$

In fact, I are comparing standards chosen under the two regimes. The first regime is a form of regulation that requires the SRO to charge membership fee $C>0$ and the revenue from these fees belongs to the government. Under the second regime, the SRO enforces minimum profit $C>0$, but does not collect any fees. In both cases, the SRO chooses 
standards to maximize the total profit of its members.

Proposition 1. Let's assume that the first-order conditions are monotonic 18 The SRO that is able to restrict the number of its members by enforcing a minimum profit constraint chooses lower quality standards than the SRO that has only quality restrictions at its disposal, for any fixed fee $C$.

This result has the following intuitive explanation. Under the quality-only self-regulation, when considering an increase in quality standards $q_{S}$, the SRO takes into account only the impact on the revenues and costs of current members because marginal members make zero profit. However, under quality-and-quantity regulation, an increase in standards makes some members leave and this reduces total profit because they made positive $(C)$ profit before the change. Thus, marginal costs of increasing standards are higher under quality-and-quantity regulation; marginal revenues are the same and standards are therefore lower.

Direct comparison of standards between an organization charging zero fee $C$ and a SRO that works under quality-and-quantity regulation is not possible. The reason for that is that the sign of $\frac{\partial q_{S}}{\partial C}$ is not clear. The structure of this model is general enough to allow for both positive and negative sign of $\frac{\partial q_{S}}{\partial C}$, depending on consumers' valuation and the distribution of producers and consumers (see Example 1 in the Appendix).

\subsection{Welfare analysis}

The presence of $\mathrm{CO}$ or SRO improves welfare-without these institutions, unobservable, costly and endogenous quality leads to only zero quality products being traded in the equilibrium. However, since neither profit-maximizing CO nor SRO take directly into account the impact of their choice of standards and fees on the consumers, it seems likely that none of them leads to a welfare optimal outcome. I start the analysis with the optimal choice of fee $C$ and standards $q_{S}$ and compare this choice to the behavior of the SRO and CO. The total welfare is the sum of the profit of the CO/SRO (if any), the profit of producers and consumer surplus.

\footnotetext{
${ }^{18}$ This assumption is trivial in the case when there is a unique local optimum.
} 


\subsubsection{Consumers' surplus}

To compute the consumers' surplus, I derive the demand function $W(\tilde{\beta}(p, q)) \cdot{ }^{19}$ First, I find the marginal consumer $\tilde{\beta}(p, q)$ who is indifferent between buying a product of quality $q$ and price $p$ :

$$
U(\tilde{\beta}(p, q), M-p, q)=U(\tilde{\beta}(p, q), M, 0) .
$$

All consumers with $\beta>\tilde{\beta}(p, q)$ prefer not to buy, while consumers $\beta \leq \tilde{\beta}(p, q)$ will buy. The demand is thus

$$
W(\tilde{\beta}(p, q))=\int_{0}^{\tilde{\beta}(p, q)} w(\beta) d \beta .
$$

The consumer surplus is then

$$
C S\left(p^{*}, q^{*}\right)=\int_{p^{*}}^{\infty} W(\tilde{\beta}(p, q)) d p
$$

Trivially, an increase in quality $q$ leads to an increase in consumers' surplus if the price remains constant.

\subsubsection{Total welfare}

Using the previous definition of consumers' surplus, I can define total welfare as the sum of the profit of the certifier, firms and consumer surplus

$$
\begin{aligned}
W= & C F\left(\alpha^{*}\left(C, q_{S}\right)\right)+\int_{p^{*}\left(C, q_{S}\right)}^{\infty} W\left(\tilde{\beta}\left(p, q_{S}\right)\right) d p+ \\
& +\int_{0}^{\alpha^{*}\left(C, q_{S}\right)}\left(p^{*}\left(C, q_{S}\right)-g\left(q_{S}, \alpha\right)-C\right) f(\alpha) d \alpha .
\end{aligned}
$$

Since the certification fee $C$ is a pure transfer that restricts supply and demand even in the situation where there would be a space for trade at zero fee, one can easily show that the welfare is optimal when the fee is equal to $C=0$.

\footnotetext{
${ }^{19}$ In this section, I use again $\tilde{\beta}(p, q)$ instead of $\beta^{*}\left(C, q_{S}\right)$ as I analyze the consumers' surplus that depends on prices and the quality.
} 
Proposition 2. Welfare optimum is reached in the point where $C=0$.

Two conditions will be useful for the following analysis. The first condition holds when marginal costs increase more than utility as a result of a marginal increase in standards in equilibrium.

\section{Condition 1.}

$$
\frac{\mathrm{d}}{\mathrm{d} q_{S}} g_{q_{S}}\left(q_{S}, \alpha^{*}\left(q_{S}, C\right)\right)>\frac{\mathrm{d}}{\mathrm{d} q_{S}} \frac{U_{q_{S}}}{U_{M}}
$$

The second condition holds if producers appropriate less than the marginal change in consumers' surplus when standards marginally change.

Condition 2.

$$
F\left(\alpha^{*}\left(C, q^{C O}\right)\right) \frac{\partial p\left(C, q^{C O}\right)}{\partial q_{S}}<\int_{p^{*}\left(C, q_{S}\right)}^{\infty} w\left(\tilde{\beta}\left(p, q^{C O}\right)\right) \frac{\partial \tilde{\beta}\left(p, q^{C O}\right)}{\partial q} d p
$$

Note that since this condition characterizes only marginal effects, it is theoretically possible that the condition does not hold: when standards change, the profit of the producers may increase more than the surplus of the consumers.

\subsubsection{The comparison of standards and welfare}

Even though the SRO chooses zero fee $C$, I cannot in general expect its choice of quality standard $q_{S}$ to be welfare-optimal because it only maximizes the profit of its members. I confirm this intuition by showing that only when the SRO can fully extract a marginal increase in consumers' surplus due to an increase in standards, the choice of standard will be welfare-optimal.

Proposition 3. The standards chosen by the SRO charging zero fee, $C=0$, are welfare optimal only if the producers are able to fully appropriate the marginal increase in consumers' surplus in equilibrium, ie., when Condition 2 holds with equality for $C=0$.

In case the SRO is not able to do so, it will choose welfare-suboptimal standards ${ }^{20}$ The

\footnotetext{
${ }^{20}$ Note that the ability to fully extract the marginal increase does not imply the ability to extract all surplus. It may happen that the SRO is able to extract a small portion of the surplus for very low levels of quality, but that this portion increases as the quality increases. Thus, it is even theoretically possible that the SRO is able to extract more than the marginal increment in the surplus.
} 
following result shows when such standards will be lower than welfare-optimal.

Proposition 4. Assume fee $C=0$ is fixed. If Condition 2 holds at $q_{S}=q^{W O}$ and $C=0$, and if the first order conditions for the SRO are monotonic in $q_{s}$, then $q^{S R O}<q^{W O}$ in equilibrium.

Next, I compare standards chosen by the CO and SRO if they charge the same fee $C$.

Proposition 5. Assume $C$ is fixed. If and only if Condition 1 holds, the SRO chooses higher quality standards than the CO.

This result does not allow us to compare standards chosen for different fees. ${ }^{21}$ However, it is valid for all fees $C$, not necessarily the optimal or zero one. The proof of this result is based on the following intuition. The certifier chooses standards so that the change in costs and prices is equal each other for the marginal producers (to maximize participation). This is suboptimal for self-regulation, because other participating producers face lower marginal costs than the marginal change in price (and revenues). Thus, the SRO chooses quality so that the marginal costs for the marginal producer are higher than the marginal revenue. Under the condition from this proposition, this happens only when standards are higher than those chosen by the CO.

Also, one can combine the previous results to compare standards chosen by the CO and welfare optimal standards.

Proposition 6. Let's assume that the welfare function has only one optimum in the relevant range..$^{22}$ If Condition 2 holds, then the CO chooses lower standard than is welfare optimal for exogenously given fee $C$.

The result is similar to Proposition 4. It shows that the ability of the CO to extract rent determines quality standards. Combining results from Propositions 4, 5 and 6 gives the following corollary.

\footnotetext{
${ }^{21}$ The comparison of standards for different fees is not possible because it is not clear what effect a change in fee $C$ will have on the standards chosen by the SRO. Using the Implicit Function Theorem, one can show that such effect is non-linear and its sign cannot be determined without restrictive assumptions.

In the appendix, I show that it is possible, at $C=0$, for the SRO to choose higher and lower standards than standards chosen by the $\mathrm{CO}$ at the fee of its choice.

${ }^{22}$ This range is $\left[\min \left\{q^{C O}(C), q^{W O}(C)\right\}, \max \left\{q^{C O}(C), q^{W O}(C)\right\}\right]$, where $q^{W O}(C)$ is a welfare optimal standard for an exogenously given fee $C>0$. This condition is satisfied if, for example, the welfare function is differentiable and single peaked.
} 
Corollary 1. If Conditions 1 and 2 hold for a given $C$, the standards satisfy

$$
q^{W O}(C)>q^{S R O}(C)>q^{C O}(C)
$$

Finally, I show that a comparison of standards for different fees is not possible.

Proposition 7. In equilibrium, standards chosen by a self-regulatory organization can be higher or lower than those chosen by a certifying organization.

In the appendix, I present two examples that differ in the production costs only. In one case, the SRO chooses a higher standard than the CO, while the opposite is true in the other example. Thus, it is not possible to make a comparison of standards for different fees.

\subsection{Extension-not-for-profit certifiers}

Next, I extend the analysis by considering the behavior of not-for-profit certifiers. I focus on the maximization of revenue, standards and number of certified firms.

\subsubsection{Revenue maximization}

Let's assume that the certifier maximizes total revenue of the certified producers. Since producing quality is costly, this is not equivalent to the total profit-maximization done by the SRO. Thus, the certifier chooses fee $C$ and quality standards $q_{S}$ to maximize

$$
\max _{C, q_{S}} \int_{0}^{\alpha^{*}\left(C, q_{S}\right)}\left(p\left(C, q_{S}\right)\right) f(\alpha) d \alpha=\max _{C, q_{S}} F\left(\alpha^{*}\left(C, q_{S}\right)\right) p\left(C, q_{S}\right) .
$$

Proposition 8. The producers' revenue maximizing certifier will choose higher standards than the profit-maximizing certifier for any given $C$ if and only i. ${ }^{23}$ Condition 1 holds.

In contrast to the profit-maximizing certifier, the producers' revenue maximization $\mathrm{CO}$ thus chooses higher standards for any given $C$.

\footnotetext{
${ }^{23}$ Note that this condition is rather weak. In particular, if an increase in standards reduces marginal valuation of quality $U_{q_{S}}$, but increases prices and thus increases $U_{M}$, the right-hand side will be negative, while the left-hand side is positive if $\alpha^{*}$ increases.
} 


\subsubsection{Maximization of the number of certified producers}

Let's analyze the behavior of the $\mathrm{CO}$ that maximizes the total number of certified organizations.

$$
\max _{q_{S}, C} F\left(\alpha^{*}\left(C, q_{S}\right)\right)
$$

It is easy to show that because increasing fee $C$ reduces participation for given standards (Lemma 1), the CO maximizing the number of certified producers will choose zero fee. I compare the standards it will choose with the SRO that also prefers fee $C=0$.

Proposition 9. The optimal standards are lower than those chosen by the SRO if and only if Condition 1 holds.

Note that the standards chosen by a certifier that maximizes the number of certified producers and its own profit are the same for fixed fee $C$. Their behavior differs in the choice of fees, not standards.

\subsubsection{Standards maximization}

Let's assume that the CO maximizes the standards, subject to participation constraints. Intuitively, a zero market size is to be expected. On such market, consumers of the highest valuation $(\beta=0)$ trade with producers with the lowest production costs $(\alpha=0)$. Obviously, the fee $C$ is set to zero. Neither consumers nor producers have a positive surplus-price corresponds to the production costs, which corresponds to the valuation of the good. The maximal price as a function of quality is implicitly defined by the equation

$$
U\left(0, M-p_{\max }, q_{\max }\right)=U(0, M, 0) .
$$

The lowest price that a producer of the lowest costs is willing to accept for a good of quality $q_{\max }$ is

$$
p=g\left(q_{\max }, 0\right) .
$$


The maximal quality that can be produced on the market is

$$
U\left(0, M-g\left(q_{\max }, 0\right), q_{\max }\right)=U(0, M, 0) .
$$

Note that this problem may have an unbounded solution. For example, if $U_{q}>0$ and $g(q, 0)=g_{q}(q, 0)=0$, the highest possible standards are infinite. ${ }^{24}$ Obviously, this is a degenerate case that does not require further study.

\subsection{Extension 2-costly testing technology}

So far, I have assumed that both $\mathrm{CO}$ and SRO possess costless and perfect testing technology. In this section I analyze the situation in which costs of certification and self-regulation are positive. I do not assume that the costs differ between the $\mathrm{CO}$ and SRO, even though this seems quite likely. I postpone the discussion of the difference in the cost to the appendix. However, I do not intend to show that certification is cheaper than self-regulation (or vice-versa). Instead, I study how costs influence the choice of fee and standards analyzed in the previous section. For simplicity, I study only for-profit certification and total-profit maximization self-regulation. It is obvious that purely fixed costs would not affect the decision of the CO, who needs to cover them to remain in the market. It would, however, force the SRO to charge a positive fee. Depending on the size of these costs, the SRO will be behaving somewhat similarly to the CO. If these fixed costs are as large as the potential profit of the profit-maximizing $\mathrm{CO}$, the $\mathrm{SRO}$ would have to behave exactly as the $\mathrm{CO}$ - it is not possible to extract the same amount from the producers in another, for them preferred, way ${ }^{25}$

However, it is not possible to analyze the general cost function. Instead, I focus on constant marginal cost technology - each tests costs $\delta>0$.

\footnotetext{
${ }^{24}$ Note that these assumptions require $g(0,0)=g_{q}(0,0)=0$, but do not specify $g_{q}(q, 0)$ or $g(q, 0)$ for $q>0$.

${ }^{25}$ If there was such possibility, the CO would do that and extract a little more of their profits.
} 


\subsubsection{Total-profit-maximizing SRO}

As before, I assume that the SRO charges fee $C$ and the revenues thus collected belong to the government. The case $C=0$ is of most interest but the analysis can be done more generally without any additional technical difficulty.

$$
\left.\max _{q_{S}} \int_{0}^{\alpha^{*}\left(C, q_{S}\right)}\left(p\left(C, q_{S}\right)-g\left(q_{S}, \alpha\right)-C\right) f(\alpha) d \alpha-\delta F\left(\alpha^{*}\left(C, q_{S}\right)\right), q_{S}\right)
$$

The first order condition is

$$
\int_{0}^{\alpha^{*}\left(C, q_{S}\right)}\left(\frac{\partial p\left(C, q_{S}\right)}{\partial q_{S}}-\frac{\partial g\left(q_{S}, \alpha\right)}{\partial q_{S}}\right) f(\alpha) d \alpha-\delta \frac{\partial \alpha^{*}\left(C, q_{S}\right)}{\partial q_{S}}=0
$$

Lemma 1 and Lemma 3 show that the SRO operates in the range of standards where an additional increase in standards leads to lower participation. In the case of positive constant marginal costs, the SRO benefits more from increasing the standard because it will have to certify less producers. Thus, these costs increase standards chosen by the SRO.

\subsubsection{Profit-maximizing CO}

The objective function of the profit-maximizing $\mathrm{CO}$ facing positive marginal costs $\delta$ is

$$
\max _{C, q_{S}}(C-\delta) F\left(\alpha^{*}\left(q_{S}, C\right)\right)
$$

The first order conditions are

$$
\begin{aligned}
& {[C]: F\left(\alpha^{*}\left(C, q_{S}\right)\right)+(C-\delta) f\left(\alpha^{*}\left(C, q_{S}\right)\right) \frac{\partial \alpha^{*}\left(C, q_{S}\right)}{\partial C}=0} \\
& {\left[q_{S}\right]: \quad(C-\delta) f\left(\alpha^{*}\left(C, q_{S}\right)\right) \frac{\partial \alpha^{*}\left(C, q_{S}\right)}{\partial q_{S}}=0}
\end{aligned}
$$

One can see that the decision about $q_{S}$ did not change. Compared to the costless technology case,

$$
[C]: F\left(\alpha^{*}\left(C, q_{S}\right)\right)+C f\left(\alpha^{*}\left(C, q_{S}\right)\right) \frac{\partial \alpha^{*}\left(C, q_{S}\right)}{\partial C}=0 .
$$


The second term in the first FOC is negative $\left(\frac{\partial \alpha^{*}\left(C, q_{S}\right)}{\partial C}<0\right)$ but smaller than before $(C-\delta)$, ceteris paribus. This implies a necessary reduction in the number of applicants $F\left(\alpha^{*}\left(C, q_{S}\right)\right)$. Since the quality decision did not change, reduction in participants comes only from an increase in fees $C$.

This result is not surprising in light of our previous conclusions. The CO always chooses standards so that the number of applying producers is maximized for a given fee $C$. Since the testing gets more expensive, it wants to reduce the number of applicants. The optimal way to do so is by increasing fees. This nicely contrasts with the SRO that does not increase the fees, but increases quality standards, which reduces the number of producers applying for membership.

Under fixed costs, the SRO has to charge a positive fee to cover these costs, but it chooses to charge the lowest fee possible. Fixed costs thus motivate the SRO to increase its size and this can be done only via reduced standards. Obviously, these two effects have the opposite direction.

\section{Conclusion and Discussion}

In this paper, I present the unified model of certification and self-regulation and analyze its properties in order to compare the behavior of self-regulatory organizations and certifying organizations. The ability to extract the marginal rents from consumers determines whether the standards of the SRO will be optimal or not. Because the welfare optimal fee is zero, the behavior of the profit-maximizing $\mathrm{CO}$ is never welfare optimal. I also study conditions under which the SRO is forced to charge positive fee $C>0$. If the marginal production costs $g_{q_{S}}$ are increasing in quality $q$ more than the (relative) marginal consumer valuation $\frac{U_{q_{S}}}{U_{M}}$, then the SRO chooses higher quality standards. Finally, I show that under mild conditions on the welfare function, the $\mathrm{CO}$ will choose lower standards than would be welfare optimal even for any exogenously given fee $C>0$.

All these quality comparisons are possible only under the assumption that the fees are the same. Therefore, they do not let us to compare standards actually chosen by the SRO 
$(C=0)$ and $\mathrm{CO}(C>0)$. However, I show that the SRO may choose higher or lower quality than the CO, using two simple examples. Because the impact of an exogenously given fee on standards chosen by the SRO is ambiguous, it is not possible to identify precise conditions which would determine whether the SRO will choose higher or lower standards in a general setting.

I also study the form of regulation of the SRO. If the SRO is allowed to impose both quality standards and limit the number of its participants, it will choose lower standards than the SRO that can use only quality as a restriction of entry. This is a generalization of Shaked and Sutton (1981).

I have also discussed the impact of the objective function of a certifier on the quality and fee chosen. I have shown that if Condition 2 holds, a CO that maximizes the revenue of producers will choose higher standards than the (its own) profit-maximizing CO. Moreover, the $\mathrm{CO}$ that maximizes the number of certified organizations chooses zero fee $C$ and lower standards than the SRO, if Condition 1 holds. The standard-maximizing CO leads to a corner solution-one unit of good traded, zero profit and consumers' surplus.

Finally, I have analyzed the case of costly testing technology. If there are positive constant marginal costs, the SRO chooses higher standards, while the CO increases the fee but does not change standards.

Thus, this model provides some evidence that the SRO may often be more favorable relative to profit-maximizing certification. When the testing technology is perfect, it chooses lower fees and if it is able to fully extract marginal change in consumer surplus when standards change, it chooses optimal standards. Not-for-profit certification may be a more suitable alternative to self-regulation than a for-profit one. A certifier maximizing the number of certified producers is likely to choose lower standards but will choose an optimal fee. The certifier who maximizes producers' revenue will (under mild conditions) choose higher standards than the for-profit certifier, but will choose positive fees.

This modeling approach has several limitations. I assume perfect testing technology for the CO and SRO. This assumption significantly simplifies the analysis because it allows us to focus on one level of quality - a standard. I can abstract from the game between the SRO 
(who tries to establish quality that benefits everybody) and its members (who would prefer if only others produce high quality).

It is clear that perfect detection technology does not in fact exist. Since mistakes happen, firms for whom it is cheap to produce high quality goods might prefer to over-invest to reduce the probability of an unfavorable error, while firms with high costs for producing quality goods might be willing to take some risks and under-invest in quality. This analysis does not allow us to capture these effects.

If the testing technology is imperfect, the mechanism of certification (De and Nabar 1991) and self-regulation (Nunez 2001, 2007) work less efficiently. Some producers may be able to pass the test despite the fact that they do not meet the required standards. This has an impact on the quality expectations of consumers and thus price of the products and on other producers. Results by Nunez $(2001,2007)$ seems to suggest that this impact may be particularly strong in the case of self-regulation. In such case, this analysis is biased in favor of self-regulation. While relaxing the assumption of perfect testing technology does not seem possible due to the complexity of the resulting model, it may be possible to remove the bias by assuming more expensive testing technology for the SRO. For example, such assumption may be justified by more expensive negotiations between various members of the SRO or by the need for higher payments to the management of the SRO to enforce the standards. Then, these results that seem to favor self-regulation may no longer be valid, depending on these additional costs for the SRO.

\section{Reference}

Akerlof, G. A. (1970): "The Market for 'Lemons': Quality Uncertainty and the Market Mechanism," The Quarterly Journal of Economics, 84(3), 488-500.

Biglaiser, G. (1993): "Middlemen as Experts," RAND Journal of Economics, 24(2), 212223.

Biglaiser, G., AND J. W. Friedman (1994): "Middlemen as guarantors of quality," International Journal of Industrial Organization, 12, 509-531.

DE, S., AND P. NABAR (1991): "Economic implications of imperfect quality certification," Economics Letters, 37(4), 333-337.

Kleiner, M. M. (2006): Licensing Occupations:Ensuring Quality or Restricting Competition. W.E. Upjohn Institute for Employment Research. 
Leland, H. E. (1979): "Quacks, Lemons, and Licensing: A Theory of Minimum Quality Standards," The Journal of Political Economy, 87(6), 1328-1346.

LIZZERI, A. (1999): "Information revelation and certification intermediaries," The RAND Journal of Economics, 30(2), 214-231.

Nunez, J. (2001): "A model of self-regulation," Economic Letters, 74, 91-97.

(2007): "Can self regulation work?: a story of corruption, impunity and cover-up," Journal of Regulatory Economics, 31(2).

Ortmann, A., K. Svitkova, and A. Krnacova (2005): "Certification As A Viable Quality Assurance Mechanism in Transition Economies: Evidence, Theory and Open Questions," in Feasibility study on establishing a certification system for nonprofit organizations in the Czech Republic, pp. 7-46. Transparency International-Czech Republic, Prague.

Podhorsky, A. (2006): "Environmental Labeling," http://www.cergeei.cz/pdf/events/papers/060220_t.pdf, Job Market Paper.

Shaked, A., And J. Sutton (1981): "The Self-Regulating Profession," The Review of Economic Studies, 48(2), 217-234.

Shapiro, C. (1986): "Investment, Moral Hazard, and Occupational Licensing," The Review of Economic Studies, 53(5), 843-862.

StRAusz, R. (2005): "Honest certification and the threat of capture," International Journal of Industrial Organization, 23(1-2), 45-62.

Svitkova, K., And A. Ortmann (2006): "Certification As A Viable Quality Assurance Mechanism: Theory and Suggestive Evidence," Internet:http://www.cergeei.cz/pdf/wp/Wp288.pdf, CERGE-EI Working paper 288.

\section{Appendix}

Proof of Lemma 1. Using the defining equations of $p^{*}\left(C, q_{S}\right), \alpha^{*}\left(C, q_{S}\right), \beta^{*}\left(C, q_{S}\right)$,

$$
\begin{aligned}
F_{1}: & p^{*}\left(C, q_{S}\right)-C-g\left(q_{S}, \alpha^{*}\left(C, q_{S}\right)\right)=0 ; \\
F_{2}: & \int_{0}^{\beta^{*}\left(C, q_{S}\right)} w(\beta) d \beta-\int_{0}^{\alpha^{*}\left(C, q_{S}\right)} f(\alpha) d \alpha=0 ; \\
F_{3}: & U\left(\beta^{*}\left(C, q_{S}\right), M-p^{*}\left(C, q_{S}\right), q_{S}\right)-U\left(\beta^{*}\left(C, q_{S}\right), M, 0\right)=0 .
\end{aligned}
$$


I compute the matrix of first derivatives and use it to do comparative statics using the Implicit Function Theorem:

$$
\left(\begin{array}{ccc}
1 & -g_{\alpha}(q, \alpha) & 0 \\
0 & -f\left(\alpha^{*}\right) & w\left(\beta^{*}\right) \\
-U_{M} & 0 & U_{B}
\end{array}\right)
$$

Using the vector

$$
\left(-\frac{\partial F_{1}}{\partial C},-\frac{\partial F_{2}}{\partial C},-\frac{\partial F_{3}}{\partial C}\right)^{\prime}=(1,0,0)^{\prime}
$$

and Cramer's rule, one gets

$$
\begin{aligned}
& \frac{\partial p^{*}\left(C, q_{S}\right)}{\partial C}=\frac{\left|\begin{array}{ccc}
1 & -g_{\alpha}(q, \alpha) & 0 \\
0 & -f\left(\alpha^{*}\right) & w\left(\beta^{*}\right) \\
0 & 0 & U_{\beta}
\end{array}\right|}{\left|\begin{array}{ccc}
1 & -g_{\alpha}(q, \alpha) & 0 \\
0 & -f\left(\alpha^{*}\right) & w\left(\beta^{*}\right) \\
-U_{M} & 0 & U_{\beta}
\end{array}\right|}=\frac{-f\left(\alpha^{*}\right) U_{\beta}}{-f\left(\alpha^{*}\right) U_{\beta}+U_{M} g_{\alpha}(q, \alpha) w\left(\beta^{*}\right)}>0 \\
& \frac{\partial \alpha^{*}\left(C, q_{S}\right)}{\partial C}=\frac{\left|\begin{array}{ccc}
1 & 1 & 0 \\
0 & 0 & w\left(\beta^{*}\right) \\
-U_{M} & 0 & U_{\beta}
\end{array}\right|}{\left|\begin{array}{ccc}
1 & -g_{\alpha}(q, \alpha) & 0 \\
0 & -f\left(\alpha^{*}\right) & w\left(\beta^{*}\right) \\
-U_{M} & 0 & U_{\beta}
\end{array}\right|}=\frac{-U_{M} w\left(\beta^{*}\right)}{-f\left(\alpha^{*}\right) U_{\beta}+U_{M} g_{\alpha}(q, \alpha) w\left(\beta^{*}\right)}<0
\end{aligned}
$$




$$
\frac{\partial \beta^{*}\left(C, q_{S}\right)}{\partial C}=\frac{\left|\begin{array}{rrr}
1 & -g_{\alpha}(q, \alpha) & 1 \\
0 & -f\left(\alpha^{*}\right) & 0 \\
-U_{M} & 0 & 0
\end{array}\right|}{\left|\begin{array}{ccc}
1 & -g_{\alpha}(q, \alpha) & 0 \\
0 & -f\left(\alpha^{*}\right) & w\left(\beta^{*}\right) \\
-U_{M} & 0 & U_{\beta}
\end{array}\right|}=\frac{-f\left(\alpha^{*}\right) U_{M}}{-f\left(\alpha^{*}\right) U_{\beta}+U_{M} g_{\alpha}(q, \alpha) w\left(\beta^{*}\right)}<0 .
$$

Note that

$$
\begin{gathered}
U_{\beta}<0, U_{M}>0, g_{\alpha}>0, w\left(\beta^{*}\right)>0, f\left(\alpha^{*}\right) \Longrightarrow \\
-\quad f\left(\alpha^{*}\right) U_{\beta}+U_{M} g_{\alpha}(q, \alpha) w\left(\beta^{*}\right)>0,
\end{gathered}
$$

and thus

$$
1>\frac{\partial p^{*}\left(C, q_{S}\right)}{\partial C}>0, \frac{\partial \alpha^{*}\left(C, q_{S}\right)}{\partial C}<0, \frac{\partial \beta^{*}\left(C, q_{S}\right)}{\partial C}<0 .
$$

A similar analysis for $\frac{\partial}{\partial q_{S}}$ leads to

$$
\left(-\frac{\partial F_{1}}{\partial q_{S}},-\frac{\partial F_{2}}{\partial q_{S}},-\frac{\partial F_{3}}{\partial q_{S}}\right)^{\prime}=\left(g_{q_{S}}\left(q_{S}, \alpha\right), 0,-U_{q_{S}}\right)^{\prime} .
$$

Our assumptions are

$$
g_{q_{S}}\left(q_{S}, \alpha\right)>0, f\left(\alpha^{*}\right)>0, w\left(\beta^{*}\right)>0, U_{\beta}<0, U_{M}>0, U_{q}>0,
$$

which allows me to compute the signs of partial derivatives:

$$
\frac{\partial p}{\partial q_{S}}=\frac{-\left|\begin{array}{ccc}
g_{q_{S}}\left(q_{S}, \alpha\right) & g_{\alpha}(q, \alpha) & 0 \\
0 & f\left(\alpha^{*}\right) & w\left(\beta^{*}\right) \\
-U_{q_{S}} & 0 & U_{\beta}
\end{array}\right|}{\left|\begin{array}{ccc}
1 & -g_{\alpha}(q, \alpha) & 0 \\
0 & -f\left(\alpha^{*}\right) & w\left(\beta^{*}\right) \\
-U_{M} & 0 & U_{\beta}
\end{array}\right|}=-\frac{g_{q_{S}}\left(q_{S}, \alpha\right) f\left(\alpha^{*}\right) U_{\beta}-U_{q_{S}} g_{\alpha}(q, \alpha) w\left(\beta^{*}\right)}{-f\left(\alpha^{*}\right) U_{\beta}+U_{M} g_{\alpha}(q, \alpha) w\left(\beta^{*}\right)}>0
$$




$$
\begin{aligned}
& \frac{\partial \alpha}{\partial q_{S}}=\frac{\left|\begin{array}{ccc}
1 & g_{q_{S}}\left(q_{S}, \alpha\right) & 0 \\
0 & 0 & w\left(\beta^{*}\right) \\
-U_{M} & -U_{q_{S}} & U_{\beta}
\end{array}\right|}{\left|\begin{array}{ccc}
1 & -g_{\alpha}(q, \alpha) & 0 \\
0 & -f\left(\alpha^{*}\right) & w\left(\beta^{*}\right) \\
-U_{M} & 0 & U_{\beta}
\end{array}\right|}=-\frac{U_{M} g_{q_{S}}\left(q_{S}, \alpha\right)-U_{q_{S}}}{-\frac{f\left(\alpha^{*}\right)}{w\left(\beta^{*}\right)} U_{\beta}+U_{M} g_{\alpha}(q, \alpha)} \\
& \frac{\partial \beta}{\partial q_{S}}=\frac{\left|\begin{array}{ccc}
1 & -g_{\alpha}(q, \alpha) & g_{q_{S}}\left(q_{S}, \alpha\right) \\
0 & -f\left(\alpha^{*}\right) & 0 \\
-U_{M} & 0 & -U_{q_{S}}
\end{array}\right|}{\left|\begin{array}{ccc}
1 & -g_{\alpha}(q, \alpha) & 0 \\
0 & -f\left(\alpha^{*}\right) & w\left(\beta^{*}\right) \\
-U_{M} & 0 & U_{\beta}
\end{array}\right|}=-\frac{U_{M} f\left(\alpha^{*}\right) g_{q_{S}}\left(q_{S}, \alpha\right)-U_{q_{S}} f\left(\alpha^{*}\right)}{-f\left(\alpha^{*}\right) U_{\beta}+U_{M} g_{\alpha}(q, \alpha) w\left(\beta^{*}\right)} .
\end{aligned}
$$

The sign of $\frac{\partial \alpha}{\partial q_{S}}$ and $\frac{\partial \beta}{\partial q_{S}}$ depend on the relative size of $g_{q_{S}}$ and $\frac{U_{q}}{U_{M}}$. If the increase in costs of the marginal firm due to an increase in standards is bigger than the relative benefit to the consumers $\frac{U_{q}}{U_{M}}$, the size of the market decreases.

Proof of Lemma 2. Since both $C$ and $f(\alpha)$ are positive, the first order condition implies

$$
\frac{\partial \alpha^{*}}{\partial q_{S}}=0
$$

Using the derivations from the proof of Lemma 1, such condition requires

$$
U_{M} g_{q_{S}}\left(q_{S}, \alpha\right)-U_{q_{S}}=0 \Longrightarrow g_{q_{S}}\left(q_{S}, \alpha\right)=\frac{U_{q_{S}}}{U_{M}}
$$

If one plugs this result into the expression for $\frac{\partial p}{\partial q_{S}}$, one gets

$$
\frac{\partial p}{\partial q_{S}}=-\frac{\frac{U_{q_{S}}}{U_{M}} f\left(\alpha^{*}\right) U_{\beta}-U_{q_{S}} g_{\alpha}(q, \alpha) w\left(\beta^{*}\right)}{-f\left(\alpha^{*}\right) U_{\beta}+U_{M} g_{\alpha}(q, \alpha) w\left(\beta^{*}\right)}=\frac{U_{q_{S}}}{U_{M}} .
$$


By plugging this result into the expression for

$$
\frac{\partial \beta}{\partial q_{S}}=-\frac{U_{M} \frac{U_{q_{S}}}{U_{M}} f\left(\alpha^{*}\right)-U_{q_{S}} f\left(\alpha^{*}\right)}{-f\left(\alpha^{*}\right) U_{\beta}+U_{M} g_{\alpha}(q, \alpha) w\left(\beta^{*}\right)}
$$

one can obtain $\frac{\partial \beta}{\partial q_{S}}=0$.

Proof of Lemma 3. The first order conditions are

$$
\begin{aligned}
{[C]: } & \int_{0}^{\alpha^{*}\left(C, q_{S}\right)} \frac{\partial p\left(C, q_{S}\right)}{\partial C} f(\alpha) d \alpha+\frac{\partial \alpha^{*}\left(C, q_{S}\right)}{\partial C} f\left(\alpha^{*}\left(C, q_{S}\right)\right) C=0, \text { and } \\
{\left[q_{S}\right]: } & \int_{0}^{\alpha^{*}\left(C, q_{S}\right)}\left(\frac{\partial p\left(C, q_{S}\right)}{\partial q_{S}}-\frac{\partial g\left(q_{S}, \alpha\right)}{\partial q_{S}}\right) f(\alpha) d \alpha+\frac{\partial \alpha^{*}\left(C, q_{S}\right)}{\partial q_{S}} f\left(\alpha^{*}\left(C, q_{S}\right)\right) C=0 .
\end{aligned}
$$

The second of these conditions is positive if

$$
g_{q_{S}}\left(q_{S}, \alpha^{*}\left(C, q_{S}\right)\right)=\frac{U_{q_{S}}}{U_{M}} \Longleftrightarrow \frac{\partial \alpha^{*}\left(C, q_{S}\right)}{\partial q_{S}}=0 .
$$

Since

$$
g_{q_{S}}\left(q_{S}, \alpha^{*}\left(C, q_{S}\right)\right)>\frac{U_{q_{S}}}{U_{M}} \Longleftrightarrow \frac{\partial \alpha^{*}\left(C, q_{S}\right)}{\partial q_{S}}<0,
$$

and $\frac{\partial p\left(C, q_{S}\right)}{\partial q_{S}}>0$, the equilibrium may occur only if

$$
\frac{\partial p\left(C, q_{S}\right)}{\partial q_{S}}<\frac{\partial g\left(q_{S}, \alpha\right)}{\partial q_{S}}
$$

which happens if and only if

$$
g_{q_{S}}\left(q_{S}, \alpha^{*}\left(C, q_{S}\right)\right)>\frac{U_{q_{S}}}{U_{M}} .
$$

Proof of Lemma 4. Assume existence of an interior solution $q_{S}$ such that the first order condition holds. Using a contradiction, if $g_{q_{S}}\left(q_{S}, \alpha^{*}\left(C, q_{S}\right)\right) \leq \frac{U_{q}}{U_{M}}$, then

$$
\begin{aligned}
F\left(\alpha^{*}\left(C, q_{S}\right)\right) \frac{\partial p\left(C, q_{S}\right)}{\partial q_{S}} & >\frac{\partial g\left(q_{S}, \alpha^{*}\left(C, q_{S}\right)\right)}{\partial q_{S}} \int_{0}^{\alpha^{*}\left(C, q_{S}\right)} f(\alpha) d \alpha= \\
& =F\left(\alpha^{*}\left(C, q_{S}\right)\right) \frac{\partial g\left(q_{S}, \alpha^{*}\left(C, q_{S}\right)\right)}{\partial q_{S}}
\end{aligned}
$$


because $\frac{\partial g\left(q_{S}, \alpha\right)}{\partial q_{S}}$ is increasing in $\alpha$. Thus, this condition can be simplified to

$$
\frac{\partial p\left(C, q_{S}\right)}{\partial q_{S}}>\frac{\partial g\left(q_{S}, \alpha^{*}\left(C, q_{S}\right)\right)}{\partial q_{S}}
$$

It is straightforward to verify that such a condition holds only if $g_{q_{S}}\left(q_{S}, \alpha^{*}\left(0, q_{S}\right)\right)<\frac{U_{q}}{U_{M}}$, using the expression for $\frac{\partial p\left(C, q_{S}\right)}{\partial q_{S}}$ derived in the proof of Lemma 1:

$$
\frac{\partial p\left(C, q_{S}\right)}{\partial q_{S}}=-\frac{g_{q_{S}}\left(q_{S}, \alpha^{*}\left(C, q_{S}\right)\right) f\left(\alpha^{*}\right) U_{\beta}-U_{q} g_{\alpha}\left(q_{S}, \alpha^{*}\left(C, q_{S}\right)\right) w\left(\beta^{*}\right)}{-f\left(\alpha^{*}\right) U_{\beta}+U_{M} g_{\alpha}\left(q_{S}, \alpha^{*}\left(C, q_{S}\right)\right) w\left(\beta^{*}\right)},
$$

which concludes the proof.

Proof of Proposition 1. Assume that the fee $C>0$ is fixed. The optimal quality standards $q_{S}^{q}$ are defined by the equation

$$
\int_{0}^{\alpha^{*}\left(C, q_{S}\right)}\left(\frac{\partial p\left(C, q_{S}\right)}{\partial q_{S}}-\frac{\partial g\left(q_{S}, \alpha\right)}{\partial q_{S}}\right) f(\alpha) d \alpha=0
$$

in the case in which the SRO can regulate only quality. If the SRO is able to enforce minimal profit $C>0$, then the total profit optimizing standards $q_{S}^{n}$ are

$$
\int_{0}^{\alpha^{*}\left(C, q_{S}\right)}\left(\frac{\partial p\left(C, q_{S}\right)}{\partial q_{S}}-\frac{\partial g\left(q_{S}, \alpha\right)}{\partial q_{S}}\right) f(\alpha) d \alpha+\frac{\partial \alpha^{*}\left(C, q_{S}\right)}{\partial q_{S}} f\left(\alpha^{*}\left(C, q_{S}\right)\right) C=0 .
$$

I have already established that

$$
g_{q_{S}}\left(q_{S}, \alpha^{*}\left(C, q_{S}\right)\right)>\frac{U_{q_{S}}}{U_{M}}
$$

in both equilibria and thus

$$
\frac{\partial \alpha^{*}\left(C, q_{S}\right)}{\partial q_{S}}<0
$$

Thus,

$$
\int_{0}^{\alpha^{*}\left(C, q_{S}\right)}\left(\frac{\partial p\left(C, q_{S}\right)}{\partial q_{S}}-\frac{\partial g\left(q_{S}, \alpha\right)}{\partial q_{S}}\right) f(\alpha) d \alpha>0
$$

at quality $q_{S}^{n}$. Since the equality holds at $q_{S}^{q}$ (regulation of quality only) and the first order 
conditions are assumed monotonic, it follows that

$$
q_{S}^{n}<q_{S}^{q}
$$

Thus, the ability to control the number of members reduces quality standards.

Proof of Proposition 2. The maximization problem

$$
\begin{aligned}
W= & C F\left(\alpha^{*}\left(C, q_{S}\right)\right)+\int_{p^{*}\left(C, q_{S}\right)}^{\infty} W\left(\tilde{\beta}\left(p, q_{S}\right)\right) d p+ \\
& +\int_{0}^{\alpha^{*}\left(C, q_{S}\right)}\left(p^{*}\left(C, q_{S}\right)-C-g\left(q_{S}, \alpha\right)\right) f(\alpha) d \alpha
\end{aligned}
$$

has two FOC, one with respect to fee $C$ and the other with respect to standards $q_{S}$.

$$
\begin{aligned}
{[C]: F\left(\alpha^{*}\left(C, q_{S}\right)\right) } & +C f\left(\alpha^{*}\left(C, q_{S}\right)\right) \frac{\partial \alpha^{*}\left(C, q_{S}\right)}{\partial C}-\frac{\partial p^{*}\left(C, q_{S}\right)}{\partial C} W\left(\beta^{*}\left(C, q_{S}\right)\right)+ \\
& +\frac{\partial \alpha^{*}\left(C, q_{S}\right)}{\partial C}\left(p^{*}\left(C, q_{S}\right)-C-g\left(q_{S}, \alpha^{*}\left(C, q_{S}\right)\right)\right) f(\alpha)+ \\
& +\int_{0}^{\alpha^{*}\left(C, q_{S}\right)}\left(\frac{\partial p\left(C, q_{S}\right)}{\partial C}-1\right) f(\alpha) d \alpha=0
\end{aligned}
$$

Since

$$
\begin{aligned}
\int_{0}^{\alpha^{*}\left(C, q_{S}\right)}\left(\frac{\partial p^{*}\left(C, q_{S}\right)}{\partial C}-1\right) f(\alpha) d \alpha & =\left(\frac{\partial p^{*}\left(C, q_{S}\right)}{\partial C}-1\right) F\left(\alpha^{*}\left(C, q_{S}\right)\right), \\
p^{*}\left(C, q_{S}\right)-C-g\left(q_{S}, \alpha^{*}\left(C, q_{S}\right)\right) & =0 \\
F\left(\alpha^{*}\left(C, q_{S}\right)\right) & =W\left(\beta^{*}\left(C, q_{S}\right)\right)
\end{aligned}
$$

the first order condition can be rewritten as 26

$$
C f\left(\alpha^{*}\left(C, q_{S}\right)\right) \frac{\partial \alpha^{*}\left(C, q_{S}\right)}{\partial C}=0
$$

\footnotetext{
${ }^{26}$ Note that the marginal firm has zero profit.
} 
This implies $C=0$, because if $C>0$

$$
C f\left(\alpha^{*}\left(C, q_{S}\right)\right) \frac{\partial \alpha^{*}\left(C, q_{S}\right)}{\partial C}<0, \text { because } \frac{\partial \alpha^{*}\left(C, q_{S}\right)}{\partial C}<0
$$

which leads back to $C=0$. The other first order condition is

$$
\begin{aligned}
{\left[q_{S}\right]: } & C f\left(\alpha\left(q_{S}, C\right)\right) \frac{\partial \alpha^{*}\left(C, q_{S}\right)}{\partial q_{S}}+\int_{0}^{\alpha^{*}\left(C, q_{S}\right)} \frac{\partial p\left(C, q_{S}\right)}{\partial q_{S}}-\frac{\partial g\left(q_{S}, \alpha\right)}{\partial q_{S}} d \alpha+ \\
& +\int_{p^{*}\left(C, q_{S}\right)}^{\infty} w\left(\tilde{\beta}\left(p, q_{S}\right)\right) \frac{\partial \tilde{\beta}\left(p, q_{S}\right)}{\partial q} d p-\frac{\partial p^{*}\left(C, q_{S}\right)}{\partial q_{S}} W\left(\beta^{*}\left(C, q_{S}\right)\right)=0 .
\end{aligned}
$$

Under $C=0$, this condition becomes

$$
\left[q_{S}\right]:-\int_{0}^{\alpha^{*}\left(0, q_{S}\right)} \frac{\partial g\left(q_{S}, \alpha\right)}{\partial q_{S}} d \alpha+\int_{p^{*}\left(0, q_{S}\right)}^{\infty} w\left(\tilde{\beta}\left(p, q_{S}\right)\right) \frac{\partial \tilde{\beta}\left(p, q_{S}\right)}{\partial q} d p=0
$$

This condition is rather intuitive. The standards are set optimally when the change in the production costs due to an increase in standards equals the change in gross consumer surplus. ${ }^{27}$

Proof of Proposition 3. The SRO chooses the standard such that

$$
F\left(\alpha^{*}\left(0, q_{S}\right)\right) \frac{\partial p\left(0, q_{S}\right)}{\partial q_{S}}=\int_{0}^{\alpha^{*}\left(0, q_{S}\right)} \frac{\partial g\left(q_{S}, \alpha\right)}{\partial q_{S}} f(\alpha) d \alpha
$$

The welfare optimum is described by

$$
\int_{p^{*}\left(0, q_{S}\right)}^{\infty} w\left(\tilde{\beta}\left(p, q_{S}\right)\right) \frac{\partial \tilde{\beta}\left(p, q_{S}\right)}{\partial q} d p=\int_{0}^{\alpha^{*}\left(0, q_{S}\right)} \frac{\partial g\left(q_{S}, \alpha\right)}{\partial q_{S}} d \alpha
$$

By comparing these two conditions, one can see that the SRO chooses the welfare optimal level of standards if and only if

$$
\int_{p^{*}\left(0, q_{S}\right)}^{\infty} w\left(\tilde{\beta}\left(p, q_{S}\right)\right) \frac{\partial \tilde{\beta}\left(p, q_{S}\right)}{\partial q} d p=F\left(\alpha^{*}\left(0, q_{S}\right)\right) \frac{\partial p\left(0, q_{S}\right)}{\partial q_{S}} .
$$

\footnotetext{
27 "Gross consumer surplus" means the surplus change when prices are constant. The "net" consumer surplus then denotes the surplus minus the expenditures.
} 
Similar results hold in the case in which fee $C$ is exogenously set to a positive level.

Proof of Proposition 4. Let us denote

$$
G\left(q_{S}\right)=F\left(\alpha^{*}\left(0, q_{S}\right)\right) \frac{\partial p\left(0, q_{S}\right)}{\partial q_{S}}-\int_{0}^{\alpha^{*}\left(0, q_{S}\right)} \frac{\partial g\left(q_{S}, \alpha\right)}{\partial q_{S}} f(\alpha) d \alpha
$$

The welfare optimal choice of standards for fee $C=0$ is given by the condition

$$
\int_{0}^{\alpha^{*}\left(0, q^{W O}\right)} \frac{\partial g\left(q^{W O}, \alpha\right)}{\partial q^{W O}} f(\alpha) d \alpha=\left.\int_{p^{*}\left(0, q^{W O}\right)}^{\infty} w\left(\tilde{\beta}\left(p, q^{W O}\right)\right) \frac{\partial \tilde{\beta}\left(p, q_{S}\right)}{\partial q_{S}}\right|_{q_{S}=q^{W O}} d p
$$

Thus, if

$$
F\left(\alpha^{*}\left(0, q_{S}\right)\right) \frac{\partial p\left(0, q_{S}\right)}{\partial q_{S}}<\int_{p^{*}\left(0, q_{S}\right)}^{\infty} w\left(\tilde{\beta}\left(p, q_{S}\right)\right) \frac{\partial \tilde{\beta}\left(p, q_{S}\right)}{\partial q} d p
$$

at $q^{W O}$, then also

$$
F\left(\alpha^{*}\left(0, q^{W O}\right)\right) \frac{\partial p\left(0, q^{W O}\right)}{\partial q_{S}}<\int_{0}^{\alpha^{*}\left(0, q^{W O}\right)} \frac{\partial g\left(q^{W O}, \alpha\right)}{\partial q^{W O}} f(\alpha) d \alpha
$$

because, by definition of $q^{W O}$ (above),

$$
\int_{0}^{\alpha^{*}\left(0, q^{W O}\right)} \frac{\partial g\left(q^{W O}, \alpha\right)}{\partial q^{W O}} f(\alpha) d \alpha=\left.\int_{p^{*}\left(0, q^{W O}\right)}^{\infty} w\left(\tilde{\beta}\left(p, q^{W O}\right)\right) \frac{\partial \tilde{\beta}\left(p, q_{S}\right)}{\partial q_{S}}\right|_{q_{S}=q^{W O}} d p
$$

Thus, $G\left(q^{W O}\right)<0$. If $G\left(q_{S}\right)$ is decreasing, then $q^{S R O}<q^{W O}$ because $G\left(q^{S R O}\right)=0$ by definition. Note that the proof for $C>0$ would be more complicated because the government takes into account the impact of the standards on revenues from the SRO, while the SRO does not.

Proof of Proposition 5. In equilibrium the SRO chooses standards $q^{S R O}$ such that

$$
g_{q_{S}}\left(q_{S}, \alpha^{*}\left(q_{S}, C\right)\right)>\frac{U_{q}}{U_{M}}
$$

while the CO chooses standards $q^{C O}$ such that

$$
g_{q_{S}}\left(q_{S}, \alpha^{*}\left(q_{S}, C\right)\right)=\frac{U_{q}}{U_{M}} .
$$


If $C$ is fixed, then both left and right hand sides are functions of $q_{S}$ only. If the function

$$
G\left(q_{S}\right)=g_{q_{S}}\left(q_{S}, \alpha^{*}\left(q_{S}, C\right)\right)-\frac{U_{q}}{U_{M}}
$$

is increasing in $q_{S}$, then

$$
G\left(q^{C O}\right)=0, G^{\prime}\left(q^{S R O}\right)>0 \Longrightarrow q^{S R O}>q^{C O}
$$

Note that one must consider the total derivative of $g_{q s}$ and $\frac{U_{q}}{U_{M}}$ because of the indirect effect that $q_{S}$ has on prices $p^{*}$ and participation $\alpha^{*}, \beta^{*}$.

Proof of Proposition 6. For a positive fee, the welfare optimum is defined as

$$
\begin{aligned}
{\left[q_{S}\right]: \quad } & C f\left(\alpha\left(q_{S}, C\right)\right) \frac{\partial \alpha^{*}\left(C, q_{S}\right)}{\partial q_{S}}-\int_{0}^{\alpha^{*}\left(C, q_{S}\right)} \frac{\partial g\left(q_{S}, \alpha\right)}{\partial q_{S}} d \alpha+ \\
& +\int_{p^{*}\left(C, q_{S}\right)}^{\infty} w\left(\tilde{\beta}\left(p, q_{S}\right)\right) \frac{\partial \tilde{\beta}\left(p, q_{S}\right)}{\partial q} d p=0
\end{aligned}
$$

Since

$$
\frac{\partial g\left(q_{S}, \alpha^{*}\left(q_{S}, C\right)\right)}{\partial q_{S}}=\frac{\partial p\left(q_{S}, C\right)}{\partial q_{S}}=\frac{U_{q_{S}}}{U_{M}}
$$

and $g_{q_{S}}$ is increasing in $\alpha$, it is

$$
F\left(\alpha^{*}\left(C, q^{C O}\right)\right) \frac{\partial p\left(C, q^{C O}\right)}{\partial q_{S}}>\int_{0}^{\alpha^{*}\left(C, q^{C O}\right)} \frac{\partial g\left(q^{C O}, \alpha\right)}{\partial q^{C O}} f(\alpha) d \alpha
$$

I evaluate the first order condition of the welfare optimality at $q^{C O}$. Since $\frac{\partial \alpha^{*}}{\partial q_{S}}=0$, it follows that

$$
-\int_{0}^{\alpha^{*}\left(C, q_{S}\right)} \frac{\partial g\left(q_{S}, \alpha\right)}{\partial q_{S}} d \alpha+\int_{p^{*}\left(C, q_{S}\right)}^{\infty} w\left(\tilde{\beta}\left(p, q_{S}\right)\right) \frac{\partial \tilde{\beta}\left(p, q_{S}\right)}{\partial q} d p=0
$$


which is positive because

$$
\begin{aligned}
\int_{0}^{\alpha^{*}\left(C, q_{S}\right)} \frac{\partial g\left(q_{S}, \alpha\right)}{\partial q_{S}} f(\alpha) d \alpha & <F\left(\alpha^{*}\left(C, q^{C O}\right)\right) \frac{\partial p\left(C, q^{C O}\right)}{\partial q_{S}} \\
& <\int_{p^{*}\left(C, q_{S}\right)}^{\infty} w\left(\tilde{\beta}\left(p, q^{C O}\right)\right) \frac{\partial \tilde{\beta}\left(p, q^{C O}\right)}{\partial q} d p
\end{aligned}
$$

Using the monotonicity of welfare, one can conclude that the value of $q^{C O}$ is smaller than welfare optimal $q^{W O}$.

Example 1 (and proof of Proposition 7). In equilibrium, standards chosen by a selfregulatory organization at fee $C=0$ may be higher or lower than those chosen by a certifying organization at $C^{*}$, depending on the parametrization. I will provide two examples of parametrization that lead to opposite outcomes. First, I show that it may happen that the SRO chooses lower quality than the CO.

Assuming the following parametrization $g(q, \alpha)=q^{2}+q \alpha+\alpha, f(\alpha)=w(\beta)=1, U(\beta, q, M)=$ $(1-\beta) q+M-p$, one can easily show that the optimal standard for the $\mathrm{SRO}$ is $q^{S R O}=0.41$ for zero fee $C=0$. The $\mathrm{CO}$ chooses standards $q^{C O}=0.43$ and charges a fee for certification $C=0.123$.

The second example uses the following parametrization: $g(q, \alpha)=q^{3} \alpha, f(\alpha)=w(\beta)=$ $1, U(\beta, q, M)=(1-\beta) q+M-p$. In such situation, the SRO chooses standard $q^{S R O}=\sqrt{3}$. The CO chooses standard $q_{S}^{C O}=1$, which is lower than the standard chosen by the SRO.

Proof of Proposition 8. First order conditions are

$$
\begin{aligned}
& {[C]: f\left(\alpha^{*}\left(C, q_{S}\right)\right) \frac{\partial \alpha^{*}\left(C, q_{S}\right)}{\partial C} p\left(C, q_{S}\right)+F\left(\alpha^{*}\left(C, q_{S}\right)\right) \frac{\partial p\left(C, q_{S}\right)}{\partial C}=0, \text { and }} \\
& {\left[q_{S}\right]: f\left(\alpha^{*}\left(C, q_{S}\right)\right) \frac{\partial \alpha^{*}\left(C, q_{S}\right)}{\partial q_{S}} p\left(C, q_{S}\right)+F\left(\alpha^{*}\left(C, q_{S}\right)\right) \frac{\partial p\left(C, q_{S}\right)}{\partial q_{S}}=0 .}
\end{aligned}
$$

Note that for the second condition to be satisfied, the signs of $\frac{\partial \alpha^{*}\left(C, q_{S}\right)}{\partial q_{S}}$ and $\frac{\partial p\left(C, q_{S}\right)}{\partial q_{S}}$ have to be different, which means

$$
\frac{\partial \alpha^{*}\left(C, q_{S}\right)}{\partial q_{S}}<0
$$


This happens only if

$$
g_{q_{S}}\left(q_{S}, \alpha^{*}\left(C, q_{S}\right)\right)>\frac{U_{q_{S}}}{U_{M}}
$$

For the rest of the proof, see the proof of Proposition 5 comparing standards chosen by the $\mathrm{SRO}$ and $\mathrm{CO}$ for a given fee.

Proof of Proposition 9. The first order conditions of the maximization problem

$$
\begin{gathered}
\max _{q_{S}, C} F\left(\alpha^{*}\left(C, q_{S}\right)\right) \\
{\left[q_{S}\right]: \quad f\left(\alpha^{*}\left(C, q_{S}\right)\right) \frac{\partial \alpha^{*}\left(C, q_{S}\right)}{\partial q_{S}}=0} \\
{[C]: \quad f\left(\alpha^{*}\left(C, q_{S}\right)\right) \frac{\partial \alpha^{*}\left(C, q_{S}\right)}{\partial C}=0,}
\end{gathered}
$$

and results from Lemma $1 \frac{\partial \alpha^{*}\left(C, q_{S}\right)}{\partial C}<0$ show that to maximize the number of certified producers, it is optimal to choose $C=0$. Moreover, since standards are determined by condition

$$
\frac{\partial \alpha^{*}\left(C, q_{S}\right)}{\partial q_{S}}=0
$$

it is easy to show that the optimal standards are lower than those chosen by the SRO if and only if

$$
\frac{\mathrm{d} g_{q_{S}}\left(q_{S}, \alpha^{*}\left(q_{S}, C\right)\right)}{\mathrm{d} q_{S}}>\frac{\mathrm{d} \frac{U_{q_{S}}}{U_{M}}}{\mathrm{~d} q_{S}}
$$

For the detailed proof, see Proposition 9-comparison of standards chosen by the SRO and CO. 
Individual researchers, as well as the on-line and printed versions of the CERGE-EI Working Papers (including their dissemination) were supported from the following institutional grants:

- Economic Aspects of EU and EMU Entry [Ekonomické aspekty vstupu do Evropské unie a Evropské měnové unie], No. AVOZ70850503, (2005-2010);

- Economic Impact of European Integration on the Czech Republic [Ekonomické dopady evropské integrace na ČR], No. MSM0021620846, (2005-2011);

Specific research support and/or other grants the researchers/publications benefited from are acknowledged at the beginning of the Paper.

(c) Jan Mysliveček, 2008.

All rights reserved. No part of this publication may be reproduced, stored in a retrieval system or transmitted in any form or by any means, electronic, mechanical or photocopying, recording, or otherwise without the prior permission of the publisher.

Published by

Charles University in Prague, Center for Economic Research and Graduate Education (CERGE) and

Economics Institute ASCR, v. v. i. (EI)

CERGE-El, Politických vězňŭ 7, 11121 Prague 1, tel.: +420 224005 153, Czech Republic.

Printed by CERGE-EI, Prague

Subscription: CERGE-EI homepage: http://www.cerge-ei.cz

Editors: Directors of CERGE and EI

Managing editors: Deputy Directors for Research of CERGE and EI

ISSN 1211-3298

ISBN 978-80-7343-161-7 (Univerzita Karlova. Centrum pro ekonomický výzkum

a doktorské studium)

ISBN 978-80-7344-150-0 (Národohospodářský ústav AV ČR, v. v. i.) 
CERGE-EI

P.O.BOX 882

Politických vězňů 7

11121 Praha 1

Czech Republic http://www.cerge-ei.cz 